\title{
Los logros y los errores de un proceso de insurrección popular: Egipto, 2011-2014
}

\section{The achievements and errors of a process of popular insurrection: Egypt, 2011-2014}

\author{
JOSÉ CARLOS CASTAÑEDA REYES*
}

Resumen: El propósito de este trabajo es evaluar, desde una perspectiva histórica, los logros y los errores del proceso de insurrección popular que se inició en el país del Nilo el 25 de enero de 2011 y concluyó con la promulgación de la nueva Constitución egipcia en enero de 2014. Fueron cuatro años de intensa realidad histórica en los que el pueblo egipcio fue capaz de realizar las thawratâni masriyyatâni, dos "revoluciones egipcias" que buscaban alcanzar los grandes objetivos de "pan, libertad, justicia social y dignidad humana" y que acabaron por delinearse como las metas de los procesos de rebelión que el mundo atestiguó en este periodo. Notables beneficios, pero también errores muy costosos que han permitido el retorno de un régimen de control militar sobre las fuerzas populares que hicieron las "revoluciones" de 2011 y 2013, y que pretende impedir la aplicación de las medidas que lleven a un verdadero cambio económico, social y político en Egipto.

Palabras clave: movilización popular; contrarrevolución; justicia social; Constitución; coalición política; Egipto.

Abstract: The purpose of this paper is to evaluate, from a historical perspective, the major achievements of a process of popular insur-

Recepción: 29 de octubre de 2016. / Aceptación: 23 de mayo de 2017.

* Universidad Autónoma Metropolitana (Iztapalapa), mrwti@xanum.uam.mx 
rection in Egypt beginning on January 25, 2011, which concluded with the promulgation of the new Egyptian Constitution in January, 2014, while evaluating as well its notable mistakes. These were four years of intense historical reality, when the Egyptian people were able to carry out what was called the thawratâni masriyyatâni, two "Egyptian revolutions" that tried to achieve the objectives of "bread, freedom, social justice and human dignity"-which became the goals for the progress of rebellion witnessed by the world during that period. This was a time of significant achievements but also very costly mistakes that allowed the coming to power of a regime where there was military control over the popular forces that made the 2011 and 2013 "revolutions"-military control with the aim of preventing the implementation of measures for real-economic, social, political-change in Egypt.

Key words: popular mobilization; counterrevolution; social justice; Constitution; political coalition; Egypt.

\section{Nota previa}

Este trabajo fue concebido como una primera versión, o mejor, como esbozo de la conclusión de un libro sobre los movimientos populares en el Egipto contemporáneo entre 2011 y 2014. De hecho, está precedido por otros textos que escribí en este periodo y que constituyen la base de un libro en preparación (Castañeda, 2003, 2011a, 2011b, 2012, 2013, 2014, 2015, 2016 y s.f.). Estas páginas intentan ser una reflexión breve sobre lo que, me parece, fueron los grandes logros y los enormes fracasos que destruyeron la esperanza de los millones de egipcios que participaron en sus "revoluciones" buscando "pan, libertad, justicia social y dignidad humana". Objetivos simples y concretos de los que hasta la fecha se espera su consecución en el país del Nilo.

Así pues, el lector no encontrará en estas páginas un resumen detallado de los acontecimientos históricos en Egipto entre 2011 y 2014, pero sí una reflexión sobre lo que en particular considero una gran propuesta de cambio político y, sobre todo, económico-social, pendiente no sólo en el Egipto de nuestros días, sino también en el mundo. De ahí la fuerza del ejemplo 


\title{
egipcio y la importancia de su estudio. Coincido con el gran pensador egipcio Anouar Abdel-Malek:
}

\begin{abstract}
Más que nunca antes, nuestra nación árabe podría ser la mediadora, la intercesora entre diferentes culturas nacionales, estados y formaciones socioeconómicas que parecen permanecer separadas [...] Más que ningún "compromiso histórico", el desarrollo del renacimiento árabe [... revolucionario y popular que hoy atestiguamos, agrego yo] podría marcar el camino hacia una transformación global del poder mundial en nuestros tiempos y, por tanto, del mismo destino de la humanidad (1980, p. 513). ${ }^{1}$
\end{abstract}

\section{El ejemplo "revolucionario" egipcio}

El movimiento popular en Egipto, iniciado en enero de 2011 y que, desde mi punto de vista, concluyó con la promulgación de la Constitución de 2014, en enero de ese año, despertó opiniones encontradas. La primera thawra ${ }^{2}$ fue saludada como un gran movimiento democrático que provocó la caída de una dictadura de 31 años en 18 días. ${ }^{3}$ En cambio, la segunda tharera, en 2013, fue vista como un típico "golpe de Estado" del Ejército egipcio, que encumbró a un nuevo "faraón" (Castañeda, 2014, pp. 509-551, y 2013, pp. 1968-2000).

${ }^{1}$ El gran objetivo del movimiento popular era el cambio de modelo económico que ha venido padeciendo el grueso de la población egipcia. De ahí que sea necesario recordar la opinión de Ali E. Hillal Dessouki (1982, p. 83): "A menos que el gobierno proceda rápidamente a refrenar el consumo de lujo y a mejorar la mala distribución del ingreso, la recurrencia de los eventos de enero de 1977 no deberá ser una sorpresa para nadie". Hoy, luego del enero inolvidable de 2011, se aprecia la justeza de su opinión.

${ }^{2}$ Del árabe tawrwar, "suscitar, levantar, promover; excitar; agitar; rebelar, soliviantar, sublevar". De ahí, tarera, "revolución, levantamiento, alzamiento, sublevación, revuelta”, entre otros sentidos similares. Vid. Corriente, 1986, pp. 94-95. Prefiero la forma thawra, más utilizada en la literatura respectiva y con el sentido que le dan muchos egipcios ("revolución"), independientemente de los resultados del proceso de insurrección popular. No entro a la discusión teórica del concepto. Al respecto, remito al estudio de José Carlos Castañeda Reyes (2003, pp. 201-222). Thawratâni sería el término dual para referirse a "dos" revoluciones, las de 2011 y 2013, contra Hosni Mubarak y Muhammed Mursi respectivamente.

${ }^{3}$ Véase un análisis de las causas socioeconómicas y políticas del movimiento popular de 2011 en Castañeda, 2011a. Por motivos editoriales, inclú́ apenas algunas breves reflexiones sobre la gran rebelión en su fase inicial victoriosa. Luego amplié este análisis en Castañeda, 2011b y 2012, pp. 231-252. 
La perspectiva y el análisis de esos años fundamentales, de esos acontecimientos históricos vertiginosos y trascendentales en la historia del Egipto contemporáneo, son más complejos que algunas de las interpretaciones que se han hecho de este proceso de insurrección popular en el que, esencialmente, las grandes masas fueron capaces, por la vía pacífica, de dar un ejemplo de lo que se podría denominar "democracia directa" para incidir, precisa y valientemente, en la construcción de su propia historia. Como considera Achcar (2013, p. 292):

Con mucho, el mayor logro de las rebeliones árabes es que los pueblos de la región han aprendido a querer [...] Han aprendido a demostrar su voluntad democrática en la forma más radical [...] aquella que se expresa en las calles, cada vez que el pueblo quiera. Los trabajadores, los desempleados y los estudiantes de la región árabe han aprendido que el "poder está en las calles" y que este poder es un indispensable complemento y correctivo de aquel que viene de las urnas.

Como refuerzo de esta idea está lo que escribe Mona ElGhobashy (2011):

Las manifestaciones callejeras son una política participativa por otros medios. No compiten con los procedimientos democráticos comunes ni los afectan; profundizan la democracia al permitir más formas de actuación y al asegurar que las formas más convencionales de participación sean efectivas. Ahora que la [primera] rebelión acabó, los egipcios no confinarán su participación política a las urnas. Votarán entusiastamente si las elecciones son libres y legales, pero continuarán tomando las calles para mantener su vigilancia sobre sus nuevos gobernantes.

Muhammed Mursi y los Hermanos Musulmanes comprobaron con creces la validez de este aserto (véase Castañeda, 2014, pp. 509-551).

La ideología plasmada en los objetivos simples y concretos - "pan, libertad, justicia social y dignidad humana"- del proceso de insurrección popular encierra una lección y una enseñanza fundamentales para la humanidad de nuestros días, que se enfrenta cotidianamente a

las contradicciones objetivas del sistema capitalista [... a saber: las] guerras interminables [...] la corrupción de las élites financieras, las prác- 
ticas criminales y sádicas que violan el sentido más elemental de la justicia, la declinación constante de los niveles de vida entre la mayoría de la población trabajadora, la frustración de la juventud que siente que vive en un mundo sin futuro y sin esperanza, la grotesca exhibición de riqueza en medio de la pobreza generalizada, y la cotidiana adversidad que mucha gente enfrenta en sus vidas (North y Kishore, 2015).

Los dos movimientos populares egipcios destacan por su carácter masivo, ya que, en su primera fase, de enero a febrero de 2011, movilizaron a un mínimo de 12 millones de ciudadanos, con lo que se superó a la revolución iraní, que convocó a seis millones en sus momentos más intensos. La valentía y la resolución de los egipcios, que por medios pacíficos lograron en 18 días poner fin a un régimen de 31 años, fueron objeto de admiración mundial (North y Kishore, 2015). Después, la segunda thawra llevó a las calles a un número aún mayor de personas, tal vez el doble que la primera, que buscó y logró impedir que una dictadura religiosa remplazara la dictadura militar que habían expulsado en 2011 (Messiha y Teulon, 2013, p. 141). Los cálculos varían entre 14, 17 y 30 millones de participantes en las protestas contra el entonces presidente Muhammed Mursi, con las que se logró su caída el 3 de julio de 2013 (Mackey, 2013). ${ }^{4}$

Respecto a la cifra ( $c f r$. "Millones de egipcios exigen la renuncia del presidente Mursi”, 2013, p. 27), quizá lo mejor sea seguir la opinión de la BBC: "El número de manifestantes anti Hermandad Musulmana [es] el más grande en un acontecimiento político en la historia de la humanidad" (apud Stern, 2013b). Messiha y Teulon (2013, pp. 130-131) señalan:

los dos millones de personas que se manifestaron en enero de 2011, han sido el origen de una revolución. De la misma forma, puesto que la caída de Muhammed Mursi ha sido precedida de manifestaciones que concentraron a entre 15 y 20 millones de personas en la calle, parece difícil hablar de un golpe de Estado... [Es más] los manifestantes presentes en las principales ciudades del país han sido muchas veces más numerosos que los de la primera revolución que provocó la caída de Mubarak [...] El

${ }^{4}$ La hora es la correcta, el actor principal no, en nuestro concepto. Es bueno reflexionar, como lo hace Fatemah Farag (2013), sobre lo que ha significado para los egipcios, no para las perspectivas orientalistas occidentales, el proceso de rebelión contra Mursi y la Hermandad. 
3 de julio de 2013, el presidente Mursi fue depuesto y los Hermanos han sido expulsados por la presión de la calle. Es la amplitud de la revuelta popular (peticiones y manifestaciones de la masa) lo que ha legitimado la intervención del ejército. ${ }^{5}$

En un artículo reciente, Robert Fisk (2017, p. 13) niega enfáticamente la exageración "digna de Hollywood" de los cálculos en torno a los "millones de egipcios" que protestaron contra Mursi, y parece inclinarse, si acaso, por la cifra de un "bloguero egipcio" que afirmó: "El total de manifestantes pro Sisi que podía caber en el centro de todas las ciudades egipcias era [sic] sólo 2.8 millones". Independientemente de las cifras que se anoten, el número de egipcios fue suficiente para derribar a los dos "faraones", Mubarak y Mursi.

La justeza de la movilización popular en contra del hermano musulmán Mursi la explicó con claridad y sencillez uno de los millones de egipcios que votaron previamente por él: "Me compré una lata de atún. La abrí y el atún estaba podrido. ¿Cree usted que debo comerlo?”. ${ }^{6}$ Igualmente, al final del nuevo proceso insurreccional, "la juventud soñadora que se regocijó y bailó cuando Mursi fue depuesto”, se encontró a sí misma “en el siguiente bloque de celdas junto a la Hermandad” (Abou ElFadl, 2015, p. 265) cuando llegó la represión militar (véase Castañeda, s.f.).

He aquí la principal enseñanza del movimiento popular egipcio: la fuerza para el cambio la impulsaron los grupos sociales que, sin una "vanguardia revolucionaria" o dirigentes plenamente definidos, pusieron en jaque a un régimen corrupto que gobernó el país desde 1981 para beneficio de unos cuantos. El ejemplo de autogobierno de los días de la primera thawra también es digno de mención (El-Ghobashy, 2011, pp. 3-6).

A su vez, Elshobaki (2011, p. 108) destaca:

$\mathrm{La}$ [primera] revolución egipcia ha seguido siendo un proyecto caracterizado por su pacifismo y sus éxitos, puesto que ha logrado el primero

${ }^{5}$ Opuesta a esta perspectiva es la de Abou El-Fadl (2015, pp. 260-269), y una opinión similar tiene González del Miño (2014, p. 166).

${ }^{6} \mathrm{La}$ anécdota la recoge y explica Ismail Serageldin (2013), quien rechazó también, desde un principio, la idea de un "golpe de Estado" detrás de la caída de Mursi. 
de sus objetivos, representado por el derrocamiento de las cabezas visibles del antiguo régimen. Sólo por eso, la [primera] revolución egipcia puede considerarse la revolución por excelencia, independientemente del éxito o fracaso de su proceso de construcción. Nos encontramos, así pues, ante una experiencia que no niega su estatus como una gran revolución en la historia de la humanidad, en la que han participado más de 12 millones de personas, en un escenario sin precedentes en la historia de las revoluciones globales.

Este autor considera, empero, que los logros de esa revolución estarán incompletos mientras no se establezca una "nueva práctica política y de partidos" que consiga el gran objetivo de la "reforma del Estado" que, desde su punto de vista, deberán alcanzar "las distintas fuerzas políticas bajo la protección de una nueva Constitución y un nuevo marco jurídico" que evite el caos de otras "transiciones democráticas” que ya han llevado, primero, a un desmantelamiento del Estado, "como hicieron los estadounidenses en Iraq al disolver el Ejército y, con ello, las instituciones del Estado, lo que llevó a un desastre sin precedentes" (Elshobaki, 2011, pp. 110, 113-115).

\section{Paréntesis: el Ejército egipcio y el movimiento popular}

Precisamente en este escenario, Elshobaki le asignaba un papel fundamental al Ejército: encabezar "la transición hacia la segunda república”, ya que, al haberse negado a reprimir el primer movimiento insurreccional, reforzó la confianza de los jóvenes en las Fuerzas Armadas, pues en todo momento respetaron la voluntad popular manifiesta en la primera thawra. Es más, "la visión que el ciudadano egipcio de a pie tiene de su Ejército es la de un salvador frente a las injusticias del poder" (Elshobaki, 2011, pp. 111-112).

Aquí vale la pena recordar la reflexión del investigador Jean-Françoise Daguzan, para quien el Ejército egipcio, luego de que en la década de 1960 fue percibido como la punta de lanza en la construcción de un Estado moderno, actualmente aparece como un "modelo conservador" cuya principal preocupación es asegurar "la perennidad de los privilegios de los altos mandos” (2012, p. 21). Este autor se pregunta: “¿No son 
más que engañifas las revoluciones árabes que buscan restaurar el poder perdido de los ejércitos, como el caso egipcio podría dejarnos suponer? [...] El Egipto de hoy podría, llegada la ocasión, corresponder a esta hipótesis” (Daguzan, 2012, p. 24).

Tal afirmación es motivo de reflexión, pero también es inaceptable, pues deja fuera del proceso insurreccional la participación real, auténtica, del pueblo egipcio deseoso de mejorar sus difíciles condiciones de vida y que echó por tierra cualquier intento de control o de influencia al respecto, ya que la primera thawra rebasó de inmediato toda expectativa de intervenir subrepticiamente en ella y, en cambio, pronto encontró su camino gracias a lo justo de las demandas de los sectores populares que la impulsaron. Además, no se olvide que la primera rebelión fue el corolario de la movilización popular en el país del Nilo que, en distintas formas y con mecanismos diversos a lo largo de unos diez años, desembocó finalmente en la thawra de $2011 .^{7}$

El papel que Elshobaki le daba al Ejército en la consecución de las metas "revolucionarias" parece insostenible actualmente. Por el contrario, es la institución armada el principal obstáculo para realizar los objetivos de las "revoluciones", a pesar de que muchos egipcios todavía ven una esperanza de estabilidad en el gobierno de Al-Sisi, emanado de la institución armada. Sin embargo, la represión del movimiento popular, el encarcelamiento de los supuestos opositores al nuevo régimen, entre ellos muchos de los jóvenes revolucionarios que participaron en ambas insurrecciones, ${ }^{8}$ y la muerte de otros, son hechos que refuerzan esta imagen negativa del papel del Ejército egipcio en el proceso social. ${ }^{9}$ Recordemos el caso emblemático de Shaimaa

7 Tales antecedentes han sido analizados en Castañeda, 2011a, passim. El más remoto, pero directamente relacionado con la primera thawra, fue la gran "Rebelión por el pan", de hecho, "por la vida”, del 18 al 20 de enero de 1977, y que cobró más de 800 muertos. Vid. Castañeda, 2011a, cap. 1, pp. 21-44. Cfr. El-Ghobashy, 2011, y Abdelrahman, 2012, pp. 614-628, sobre tales antecedentes también.

${ }^{8}$ Uno de los líderes de la oposición egipcia, Abdel-Moneim Abul-Fotouh, exmiembro moderado de la Hermandad Musulmana, excandidato presidencial en 2012 y fundador del partido Egipto Fuerte, señala que en el Egipto de nuestros días hay al menos 40000 presos políticos en la cárcel (Ezzat, 2015).

${ }^{9}$ En los momentos iniciales de la primera thawra, Trager (2011, pp. 81-85) 
Al-Sabagh, asesinada por las fuerzas represivas de Al-Sisi el 24 de enero de $2015 .{ }^{10}$ También debe decirse que el Ejército egipcio no mantuvo un carácter "neutral" ni favorable al proceso de insurrección popular, como muchos observadores lo consideraron. En cambio, hoy se sabe que participó directamente en el castigo de los insurrectos desde el 25 de enero de 2011, si bien de manera un tanto encubierta, al mismo tiempo que realizaba labores de inteligencia en defensa del régimen (Stern, 2013a). Fue un augurio de la represión abierta que desarrollaría luego de la caída de Mubarak, una vez que el Consejo Supremo del Ejército Egipcio (SCAF, Supreme Council of the Armed Forces) alcanzó el poder (véase el desarrollo de esta temática en Castañeda, 2015).

Lo más inquietante y motivo de reflexión, que será imprescindible dilucidar en el futuro, es que el inicio de la primera gran rebelión del pueblo egipcio, en enero-febrero de 2011, fue precedida por hechos peculiares que deberán ser explicados a partir de una mayor perspectiva histórica o con nuevos datos que puedan recabarse. En efecto, es válido preguntarse si fueron los militares los responsables del atentado en la iglesia alejandrina de los Dos Santos (cfr. Shaoul, 2011; El-Din, 2011), ${ }^{11}$ que simbólicamente tuvo lugar a finales de 2010 y al inicio de ese crucial 2011 para Egipto, en un intento de provocar un

mostró con claridad el cambio de percepción de muchos egipcios respecto al papel de las Fuerzas Armadas en este proceso inicial: no sólo era la odiada policía del régimen, sino también los militares los que amedrentaban y reprimían a los insurrectos.

${ }^{10}$ Shaimaa, miembro de la Coalición Popular Socialista, junto con otros activistas, decidió colocar un arreglo floral en la plaza Tahrir, foco de las "revoluciones", como una forma de recordar a los muertos de los procesos de insurrección popular. El pequeño grupo volvió a cantar el lema que contiene los objetivos de la revolución: "pan, libertad, justicia social [y dignidad humana"]; fue entonces cuando, según los testigos, la policía antimotines disparó contra ellos. Shaimaa fue herida en el corazón y en un pulmón; su muerte fue rápida... Al final de la jornada, al menos otras 17 personas habían muerto (Kirkpatrick, 2015). Su caso impactó a la opinión pública, y más cuando el Ministerio del Interior culpó a un "infiltrado de la Hermandad Musulmana que buscaba culpar a la policía” de ser el causante del ataque (Ezzat, 2015). Por su parte, Al-Sisi declaró que veía a Shaimaa como a su "propia hija" (Kirkpatrick, 2015). Sobre los disturbios del cuarto aniversario de la primera thawra, véase Maged (2015).

${ }_{11}$ De tal atentado se acusó también al entonces ministro del Interior de Mubarak, Habib El-Adly. 
enfrentamiento abierto entre musulmanes y coptos para llevar al caos al país, primero con el derrocamiento de Mubarak, y luego para cerrar el paso a la Presidencia a su hijo Gamal, seguro sucesor de su padre. Y, ante la incapacidad de controlar el movimiento popular (igual opina Rutherford, 2013, pp. 4143), ¿buscaron que las Fuerzas Armadas aparecieran, otra vez, como la única salida para lograr la estabilidad y la paz social perdidas? No en balde, J. F. Daguzan (2012, p. 25) considera que el Ejército, luego de haberse desembarazado de la familia Mubarak, "jugó una partición de recomposición política con la corriente conservadora de los Hermanos Musulmanes, la opción 'Lampedusa': 'Es necesario que todo cambie para que nada cambie' (El gatopardo)”.

En efecto, estas insurrecciones populares que lograron derribar a dos "faraones" acabaron, aparentemente, canceladas por la reacción manifiesta en la represión y el control férreo, por distintos medios, de las masas egipcias por parte del ejército, en primera instancia. No otra cosa ha significado el retroceso "contrarrevolucionario" del movimiento popular que ha venido efectuando el que parece ser el "tercer faraón” del periodo, el actual mandatario egipcio, exgeneral Abdel-Fattah Said Hussein Khalil Al-Sisi, electo presidente del país y declarado como tal el 3 de junio de 2014.

Así, un movimiento popular auténtico fue cooptado por la "democracia" en un intento de desmovilizarlo y desmantelarlo. Primero con Mursi y después con Al-Sisi.

\section{De los errores de los movimientos populares egipcios}

Resulta también pertinente preguntarse acerca de las carencias y los errores del accionar de los grupos insurrectos en estos años en el país del Nilo. Al respecto, la IV Internacional Socialista encuentra que

En Egipto, todas las condiciones necesarias para una revolución estuvieron presentes, excepto una: un partido revolucionario que luchase con una perspectiva socialista internacional. Los levantamientos de masas derrocaron a los dictadores y desestabilizaron a la élite política, pero no pudieron expulsar a los militares, acabar con la ex- 
plotación y la opresión capitalistas y derrotar al imperialismo (Stern, 2013c y 2015).

Ésta es la opinión de esa organización de raigambre trotskista. Hay que decir, sin embargo, que los rebeldes egipcios nunca parecieron haber tenido planes tan ambiciosos.

Al respecto, Terry Eagleton (2011, pp. 179-195 y passim), ${ }^{12}$ por ejemplo, discute en una obra reciente las perspectivas antiguas y nuevas de lo que constituye para el marxismo un fenómeno revolucionario. Pero aquí se trata de una realidad concreta y no de una teoría sobre cómo hacer una revolución. Es la realidad concreta del país del Nilo, Egipto, entre 2011 y 2014. Y ahí se observa que el movimiento popular no logró nunca establecer un gobierno de coalición de las diversas fuerzas políticas, ni un régimen de unidad nacional, ${ }^{13}$ solución que los jóvenes que encabezaron el primer gran levantamiento en contra de Mubarak entrevieron y que se manifestó en un hipotético gobierno de un "Comité de Sabios", propuesto por los rebeldes para dirigir el país luego de la revuelta (Fisk, 2011, p. 2). Era el equivalente del gobierno de unidad nacional propuesto nuevamente a finales de enero de 2013 , cuando los enfrentamientos en el país se desbordaban en contra del gobierno de la Hermandad Musulmana. Mursi, de viaje diplomático por Alemania en ese momento, rechazó la idea con el pretexto de realizar primero las elecciones legislativas (Fahim y Kulish, 2013. Cfr. Auken, 2013).

La conformación de ese gobierno de unidad nacional, que habría sido una coalición integrada por las diversas fuerzas que participaron en el gran movimiento popular de 2011, hu-

${ }^{12}$ Es ésta una obra brillante y fundamental para entender la validez teórica y práctica del pensamiento marxista y su vertiente aplicada a la historia, el materialismo histórico. Y, de paso, para criticar la ideología reaccionaria que desde hace años pretende el "fin de la historia", el sinsentido del que bien se ocupa Josep Fontana (1992, pp. 7-16 y passim).

${ }_{13}$ Idea rechazada por Mursi en su momento y que aparecía como una de las principales propuestas para superar la aguda crisis que dejó la administración de los Hermanos. Cfr. al respecto las declaraciones de Mursi la noche del 2 de julio de 2013, cuando su caída era inminente, de integrar un gobierno de coalición y un comité para enmendar la Constitución de 2012. "Egypt presidency reiterates planned roadmap", 2013. 
biera tenido la legitimidad necesaria (que cada vez le faltaba más a Mursi y a sus apoyos, hasta su caída final) para lograr la consolidación de un nuevo sistema político de tipo parlamentario (que en la Constitución de 2014 no se estableció).

Para conseguir lo anterior, y como secuela de un gobierno de unidad nacional, el cambio verdadero en Egipto se hubiese podido alcanzar a partir de la liga entre los sectores juvenil y de trabajadores urbanos y los grupos campesinos progresistas, que habrían tenido que superar su conservadurismo para integrarse en una gran alianza que impulsara la justicia social que la primera thawera masriya o revolución egipcia había reclamado desde su inicio. El futuro de una "revolución permanente, o traicionada o secuestrada", como escriben M. Selim y G. M. Selim (2012, p. 91), dependía de la capacidad de sus actores de encontrar un compromiso entre todos. Nunca se obtuvo tal objetivo.

La llegada al poder de la Hermandad Musulmana a mediados de 2012 fue el instrumento perfecto para entorpecer toda posibilidad de unidad política.

James Petras es muy claro al respecto: la falta de un liderazgo nacional y la "espontaneidad" del levantamiento popular de 2011 le impidieron tomar el control del poder político y cumplir sus objetivos. Lo anterior permitió el reacomodo de las fuerzas reaccionarias, con el mando de los militares y el apoyo del imperialismo estadunidense garantizando que la "transición democrática" en Egipto respondiera a los intereses norteamericanos e israelíes. "Mientras que la Casa Blanca puede tolerar o incluso promover movimientos sociales para eliminar ("sacrificar") dictaduras, tiene toda la intención de preservar el Estado" (Petras, 2012, pp. 20-24). La afirmación de Petras no es "demagogia revolucionaria trillada".

Abou El-Fadl (2015, p. 269, nota 2) menciona su asistencia a una reunión con altos funcionarios norteamericanos durante la fase crítica de la Primavera Árabe. Tales personajes declararon que no era "posible dejar a los 'caprichos del proceso democrático'” sus intereses en Medio Oriente: el ejército, Camp David, asuntos de negocios, la posición norteamericana en la región y su relación con Arabia Saudita. Y concluye: "Los militares nos informaron que ésta es la posición de Estados Unidos y que 
Estados Unidos informó que el ejército debía garantizar ciertos intereses no negociables, como privilegios para el ejército norteamericano en Egipto [y los acuerdos de] Camp David, además de otros intereses que tengo prohibido mencionar". Sin comentarios en apoyo de lo dicho por Petras. ${ }^{14}$

Lo anterior confirma una hipótesis de investigación que presenté en algunos de los trabajos escritos en estos años a raíz de la victoria popular de 2011, que mostró la posibilidad de emprender un verdadero cambio estructural económico-social y político en el país del Nilo. Los sectores reaccionarios, con apoyo de Estados Unidos, emprendieron una política de represión del movimiento popular, primero con la intervención directa del ejército (febrero de 2011-junio de 2012) y luego a través de la Hermandad Musulmana, aliada coyuntural de las Fuerzas Armadas (junio de 2012-3 de julio de 2013). La Hermandad fue la herramienta "democrática" para lograrlo, pero el fracaso de su gobierno abrió el camino a una revitalización del movimiento popular que, una vez más, mediante la movilización de millones de egipcios, acabó por arrojarlos del poder el 3 de julio de 2013.

Así pues, el Ejército y los Hermanos fracasaron ante el accionar decidido del grueso de la población, que no renunció, no ha renunciado ni renunciará a lograr los objetivos fundamentales de las thareratâni masriyyatâni. Estamos, entonces, en la tercera ola represiva, en la que el Ejército utiliza la fachada de los grupos liberales afines al Antiguo Régimen para intentar, otra vez, el control del movimiento popular y, como ya se dijo,

${ }^{14}$ También Abdelrahman (2012, pp. 622, 625) considera tal posibilidad: "La élite gobernante de Egipto parece decidida a mantener el sistema económico y el orden político que empobreció a millones de egipcios y creó el ímpetu para derrocar a Mubarak. El Consejo Supremo de las Fuerzas Armadas, los Hermanos Musulmanes (HM), los remanentes de la élite empresarial, Mubarak y el Antiguo Régimen, han estado manipulando flagrantemente el proceso político con el fin de proteger sus intereses políticos y corporativos [...] los HM tienen raíces firmes dentro de la élite empresarial que se ha beneficiado de las políticas neoliberales de Mubarak. El compromiso ideológico del grupo sigue en favor de una economía de mercado libre. De manera similar, las instituciones financieras internacionales, como el Banco Mundial y el Fondo Monetario Internacional, así como los gobiernos occidentales, no quieren que Egipto, piedra angular y ejemplar de sus políticas en la región, se aleje del camino seguido por el régimen de Mubarak". 
con la complicidad norteamericana. ${ }^{15}$ Es clara la presencia de tal embate represivo antipopular. ${ }^{16}$

¿Cómo revertir esta situación? Con lo que ahora parece ser la condición indispensable para el logro de los objetivos populares: la unidad de las fuerzas progresistas del país, que nunca se dio en estos años y que, insisto, parece el error y la debilidad fundamental del proceso de rebelión popular en el país del Nilo, de aquellos que encabezaron e hicieron, junto con millones de egipcios, las dos grandes revueltas.

Al respecto, Dina Shehata (2010, pp. 64-82) analiza la fragmentación de los movimientos de oposición de izquierda en Egipto durante los últimos años previos a 2011. La cooptación, la represión selectiva, pero también las propias diferencias entre los diversos movimientos de izquierda les impidieron constituir una alternativa viable. Es igualmente la percepción crítica de Muti:

Ésta es una de las contradicciones de la escena revolucionaria egipcia, porque mientras el pueblo estaba proponiendo demandas de una agenda izquierdista y llamando a una sociedad justa, a un cambio y a un desarrollo independiente y completo, y con un sesgo por los trabajadores y los pobres en los espacios públicos y en el corazón de la plaza Tahrir, la izquierda estuvo ausente. Es decir, la izquierda estaba asombrada por la amplitud de la protesta que inundó todo lugar en Egipto, y cuando esto ocurrió, no estuvo presente como fuerza organizada que buscara movilizar a la gente y encabezar su revolución, la cual estaba impulsando demandas de naturaleza izquierdista. ${ }^{17}$

¿Cuál fue el yerro fundamental de los insurrectos que desembocó en la imposibilidad de conformar un gobierno de

${ }^{15}$ La caída de la embajadora de Estados Unidos en Egipto, Anne Patterson, anunciada el 28 de agosto de 2013, sería prueba del nuevo fracaso de tal alianza (cfr. Landler, y Taha, 2013).

${ }^{16} \mathrm{La}$ tremenda represión de cualquier intento de manifestación en el quinto aniversario de la revolución, el 25 de enero de 2016, es una prueba más de ello ( $c f r$. Morsy, 2016; Fahim, 2016, y “Off the street: How $5^{\text {th }}$ anniversary of Egypt's 2011 revolution was commemorated”, 2016). Tales políticas represivas no han variado a lo largo de ese año, 2016 (Walsh, 2016).

${ }^{17}$ El artículo de Ayman Abdel Muti (2013, pp. 13-14) es una aguda reflexión sobre esta miopía de la izquierda egipcia, de consecuencias desastrosas para el movimiento popular, como se observa ahora. Abdelrahman (2012, p. 625) también considera que a la izquierda egipcia le falta un largo camino por recorrer para establecer "lazos orgánicos con la clase trabajadora”. 
unidad nacional, que hubiese sido fundamental para el proceso de consolidación de la primera rebelión? Veamos.

En la primera vuelta de elección presidencial de 2012, Hamdeen Sabahi, el candidato nasserista del Partido de la Dignidad, obtuvo $20.72 \%$ de los votos, casi empatado con el último primer ministro de Mubarak, Ahmed Shafiq, representante del Antiguo Régimen. Sabahi, junto con Abdel Moneim Abul-Fotouh, el líder más liberal de la Hermandad y finalmente expulsado de ella, y Amr Moussa, cuarto y quinto lugar en la primera vuelta, tuvieron juntos más de 11 millones de votos, $49.32 \%$ de la votación (Stern, 2012). Y lo peor: con sus votos sumados, Sabahi y Abul-Fotouh, uno u otro, habrían derrotado a Mursi y a Shafik en la segunda vuelta de la misma elección, la única verdaderamente democrática del periodo que estudio aquí. Al final, el representante de la Hermandad, Mursi, fue elegido presidente, con los desastrosos resultados ya conocidos, que llevaron a un segundo proceso de insurrección popular aún más importante en 2013 que permitió a Al-Sisi y al Ejército "reaparecer” - aunque siempre estuvieron ahí- en la escena política del país como una aparente solución con barniz civil a la inestabilidad social que se inició en 2011 y que no ha rendido, hasta ahora, los frutos de justicia social que muchos egipcios esperaban:

Estos días camino en las calles hablando conmigo mismo. Teníamos la esperanza de que las circunstancias económicas mejoraran después de que el gobierno anunció grandes proyectos, como el del nuevo canal de Suez y el descubrimiento de enormes reservas de gas natural en el Mediterráneo. Luego, después de toda la fanfarria, los funcionarios discretamente declararon que tomará años antes de que algún proyecto rinda frutos... Nosotros no podemos vivir de promesas vacías (testimonio de Mohamed Hisham, de 55 años, en Morsy, 2015).

\section{Epílogo: ¿la última esperanza fallida? La Constitución de 2014}

Publiqué recientemente (Castañeda, 2016, pp. 137-162) un estudio sobre la Constitución de 2014 que recoge, a pesar de las discusiones sobre su redacción, los grandes logros que las ma- 
sas alcanzaron en el periodo (Constitution of the Arab Republic of Egypt 2014), y al cual remito al lector. Tan sólo destaco aquí el gran objetivo de la búsqueda de igualdad social que aparece en diversos artículos constitucionales, como el $8 .^{\circ}$, del $17 .^{\circ}$ al $21 .^{\circ}$ y el $23 .^{\circ}$ (que establecen gastos porcentuales mínimos del PNB para salud pública, 3\%; a educación básica, 4\%; a educación superior, 2\%; y a investigación científica, $1 \%$ ), o el 27. ${ }^{\circ}$ (el sistema económico debe favorecer la justicia social, no el enriquecimiento egoísta de unos cuantos).

En esta perspectiva destaca también el artículo 38, que establece los impuestos progresivos como medio para lograr la justicia social, planteamiento que ha sido puesto en práctica recientemente. Al respecto, el abogado y activista Ibrahim Salamoni expresó: “¿Cómo puede implementarse la justicia social si alguien que gana 1 millón de libras egipcias paga la misma tasa impositiva que el que gana 5000 libras egipcias?" (Ali, 2013).

Otros artículos, como el $78 .^{\circ}$ (sobre vivienda digna), o el 79. (sobre alimentación adecuada y autosuficiencia alimentaria), enfocan el mismo problema.

Lo anterior constituye obligaciones sociales para el Estado que representan una aguda carga presupuestal e implican la necesaria reforma del sistema económico para permitir un reparto más justo de la riqueza y alcanzar la justicia social para el pueblo egipcio, objetivo primario de su rebelión.

Un texto constitucional es la base jurídica fundamental de cualquier democracia moderna. Su importancia es tal que, actualmente, uno de los objetivos primordiales de la reacción antipopular en Egipto se orienta a suprimir sus posibles alcances. En efecto, luego de que Al-Sisi declarara el 13 de septiembre de 2015 que "la Constitución de Egipto de 2014 fue escrita con buenas intenciones, [pero] las naciones no pueden ser construidas tan sólo sobre buenas intenciones”, se organizó una Campaña Popular para enmendar la Constitución. Frente a ésta surgió de inmediato el Frente Nacional para Proteger la Constitución (Dawoud, 2015). Este segundo frente parece tener pocas probabilidades de éxito al confirmarse el triunfo, en las elecciones legislativas egipcias celebradas entre octubre y diciembre de 2015 (El-Din, 2015), de miembros del nuevo 
parlamento proclives incondicionalmente a Al-Sisi (Morsy, 2015. Cfr. "Touring Polling Stations", 2015). ${ }^{18}$

El posible socavamiento de la Constitución comprometerá sin duda las posibilidades de alcanzar las metas que se propusieron las dos rebeliones y el cambio a la manera que lo explica Elshobaki (2011, pp. 107-117).

Al iniciar el estudio del movimiento popular egipcio, de trascendencia mundial tanto por sus ejemplos como por sus errores, escribí que sus resultados, fuesen los que fuesen, deberían evaluarse al menos cinco años después de su conclusión. Creo que tal momento fue enero de 2014, cuando se promulgó la nueva Carta Magna vigente.

Por ahora, el panorama no es alentador si se consideran la magnitud de las movilizaciones populares y las grandes metas del proceso insurreccional que, como vimos, recoge la actual Constitución. Quizá en una revisión futura sólo nos quede reflexionar, como en alguno de los estudios previos:

El proceso de lucha popular está marcado por una serie de momentos de avance y retroceso, de logros y fracasos, de victorias y derrotas, no es una senda triunfal ni tampoco una vía bloqueada permanentemente. La experiencia de la derrota del pasado contribuye a la victoria del futuro, y los pequeños logros, a pesar de la caída, se suman a los avances producto de los éxitos de las etapas posteriores (Castañeda, 2003, p. 223).

Por lo tanto, queda la esperanza de que el pueblo egipcio pueda reclamar la consecución de las metas de justicia social que su Constitución consagra, a pesar de todo. Son preceptos constitucionales producto de la movilización popular de las dos revueltas, no graciosas concesiones de la clase dominante.

Ante ello, queda esperar la marcha de los acontecimientos. Pero que quede claro: a pesar de lo que parece un resultado sombrío del proceso de insurrección popular, las claves del cambio futuro en el país del Nilo no están en las botas del ejército, sino en las manos del propio pueblo. ¿Acaso no se

${ }^{18}$ Desde los inicios de la primera thawra, los especialistas observaban lo difícil que sería modificar el régimen presidencialista egipcio dominado por el Ejército (Goldberg, 2011, pp. 110-114). 
apreció, en vivo, por la televisión o en los videos de internet, quiénes lograron la caída de los “dos faraones”, Mubarak y Mursi? ${ }^{19}$ Como declaró uno de los actores de la segunda thawra masriya: "Tal vez la historia no tenga lados. Tal vez sólo tenga momentos. Y cuando venga el momento de ver qué hacemos con los militares, pues... bueno, vendrá". ${ }^{20}$

Algo similar escribió Maha Abdelrahaman:

Después de todo, los millones de egipcios que han tomado las calles por más de una década, durante el levantamiento popular de enero de 2011 y sus secuelas, no han estado protestando, corriendo grandes riesgos y sacrificando sus vidas para que una variedad de crony capitalism sea remplazada por un capitalismo neoliberal sin límites, determinado por una élite nacional en complicidad con los gobiernos occidentales $\mathrm{y}$ las instituciones financieras internacionales. Si no hay medidas para revertir las injusticias vividas, las demandas largo tiempo ignoradas y las cada vez más deterioradas condiciones de vida, es difícil imaginar cómo estos millones podrían ser convencidos de regresar a sus hogares y renunciar a su lucha por justicia política y social (Abdelrahman, 2012, p. 626).

Opinión parecida a lo que uno de esos millones de egipcios declaró en las protestas contra los Hermanos, y que éstos minimizaron, al considerar su pragmática alianza con las fuerzas reaccionarias:

Nosotros no pasamos tres semanas en la plaza Tahrir para establecer un Estado islámico. Fuimos ahí para traer la democracia, no para remplazar a Mubarak con [Mohamed] Badei [el guía supremo de la Hermandad].

La nuestra no fue una revolución islámica y no es posible construir un

Estado islámico a partir de esta revolución (Ezzat, 2011).

El proceso de insurrección popular egipcio retoma la disyuntiva señalada en otros trabajos: el cambio verdadero es del modelo económico que el capitalismo "neoliberal", fase superior del imperialismo capitalista, nos ha impuesto en las últimas décadas: justicia social para la mayoría del pueblo o bienestar

${ }^{19}$ Aun en análisis recientes y de gran relevancia, como el de Achcar (2013, pp. 185-187), la segunda tharera es calificada como un coup d'etat clásico. La movilización popular se diluye con tal perspectiva.

${ }_{20}$ Declaración de Said Nashar (del movimiento Tamarod) al periodista mexicano Témoris Grecko (2013, p. 56). 
egoísta de unos cuantos. Tal es la disyuntiva. No hay más. ${ }^{21}$ Por ello, el tiempo de Al-Sisi y la nueva intentona del Ejército egipcio se agota. ¿Los alcanzará una tercera thawra? El deseo de estabilidad del pueblo los sustenta por el momento; sin embargo, ¿cuánto durará esa tregua?

Egipto ha dado muestra de lo que una movilización popular auténtica y masiva, decidida y valiente puede lograr si se resuelve a ello. El pueblo egipcio retomará "su antiguo y nuevo camino”, en el que será capaz de unir la ideología libertaria del pasado con la del presente. Por ello nuestra labor de estudio de los movimientos populares en el Egipto contemporáneo enre 2011 y 2014 debe ser, con todo, optimista. Estamos seguros de que en el país del Nilo, otra vez como en el pasado, tendrá frutos la insurrección, violenta y decidida, de los sectores sociales que en su momento escenificaron uno de los movimientos populares más antiguos de que se tiene memoria, la llamada "Revolución Social" a finales del Reino Antiguo o Primer Periodo Intermedio de la historia del Egipto antiguo. Esa gran insurrección ocurrió el día que a los oídos del faraón, de los nobles y de los altos sacerdotes llegó la voz poderosa del pueblo que exclamó: "¡Vamos a expulsar a los poderosos de entre nosotros!” (Castañeda, 2003, p. 380: par. 2,7-2,8 del papiro Ipuwer, en Gardiner, 1909, p. 26. La traducción es mía, cotejada con la de diversos egiptólogos).

De la misma forma, en la Constitución egipcia de 2014 quedó plasmada también una ideología de reivindicación como resultado de la movilización popular y de su importancia ejemplar para la humanidad. Por ello, quizá podemos unir nuestras voces a las de nuestros hermanos del país del Nilo: "Somos ciudadanos, mujeres y hombres, somos el pueblo egipcio, patronos en un Estado soberano, ésta es nuestra voluntad, y ésta es la Constitución de nuestra revolución..." (Constitution of the Arab Republic of Egypt 2014), para insertarnos en nuestra propia historia.

${ }^{21}$ El artículo de Abdelrahman (2012) es muy claro al respecto, como muestra el fragmento citado. 


\section{Nota bene}

El 7 de marzo de 2017, “cientos de egipcios” en El Cairo, Alejandría, Minya, Desouk, tomaron de nuevo las calles como resultado del corte a los subsidios del pan. Su grito de protesta fue: “QQueremos comer, queremos pan!” (Niemuth, 2017). Como en 1977. Como en 2011.

\section{Ciudad de México, marzo 2017.}

Dirección institucional del autor:

Departamento de Filosofía

Universidad Autónoma Metropolitana-Iztapalapa

Michoacán y La Purísima

Col. Vicentina, Iztapalapa

09340, Ciudad de México

\section{Bibliografía}

AbDel-MaleK, A. (1980). El ocultamiento de Egipto. Tesis hacia una prospectiva. Estudios de Asia y África, 15(3), 477-514.

Abdelrahman, M. M. (2012). A hierarchy of struggles? The "economic" and the "political" in Egypt's revolution. Review of African Political Economy, 34(134), 614-628. https://doi.org/10 $.1080 / 03056244.2012 .738419$

AвоU El FADL, K. (2015). Failure of a revolution. The military, secular intelligentsia and religion in Egypt's pseudo-secular state. En L. Sadiki (Ed.), Routledge handbook of the Arab Spring. Rethinking democratization (pp. 253-270). Londres, Nueva York: Routledge.

AchCAR, G. (2013). The people want. A radical exploration of the Arab uprising. Londres: Saqi.

Ali, R. (13 de diciembre de 2013). Inside Egypt's draft constitution: Questions over social justice. Al Ahram Online. Recuperado de http://english.ahram.org.eg/NewsContent/1/64/88630/Egypt/ Politics-/-Inside-Egypts-draft-constitution-Towards-more-soc. aspx

Auken, B. (31 de enero de 2013). With death toll rising, Egypt's opposition calls for talks with Mursi. World Socialist Web Site. Recuperado de http://www.wsws.org/en/articles/2013/01/31/ egyp-j31.html 
Castañeda Reyes, J. C. (2003). Sociedad antigua y respuesta popular. Movimientos sociales en Egipto antiguo. México: UnAM, Plaza y Valdés.

Castañeda Reyes, J. C. (2011a). Egipto contemporáneo: economía, política y sociedad. México: El Colegio de México.

Castañeda Reyes, J. C. (25 y 26 de agosto de 2011b). Reflexiones sobre un movimiento popular: la "Revolución egipcia" de 2011. Trabajo presentado en el seminario internacional Protestas populares en África del norte y Medio Oriente. Un primer balance, Centro de Estudios de Asia y África de El Colegio de México. Recuperado de http://www.academia.edu/1457846/ Las_revoluciones_\%C3\%A1rabes_del_2011_y_su_significado_ hist $\% \mathrm{C} 3 \% \mathrm{~B} 3$ rico

Castañeda Reyes, J. C. (2012). El movimiento popular en Egipto en 2011: resultados primeros y tareas futuras. En L. Mesa (Coord.), El pueblo quiere que caiga el régimen. Protestas sociales y conflictos en África del Norte y en Medio Oriente (pp. 231-252). México: El Colegio de México.

Castañeda Reyes, J. C. (13-17 de agosto de 2013). De los peligros de la democracia occidental. Por la formación de un gobierno de unidad nacional en el País del Nilo. En C. Onaha y L. Rodríguez (Comps.), ALADAA XIV Congreso Internacional. Documento 1 (pp. 1968-2000). La Plata: Asociación Latinoamericana de Estudios de Asia y África.

Castañeda Reyes, J. C. (2014). "El islam [no ha sido] la solución". Egipto bajo el gobierno de los Hermanos Musulmanes (20122013). Estudios de Asia y África, 49(2), 509-551.

Castañeda Reyes, J. C. (19 de febrero de 2015). Algunas reflexiones sobre el papel del ejército en el movimiento popular egipcio (2011-2015). Ponencia presentada en la mesa redonda Medio Oriente contemporáneo: perspectivas desde México, Universidad Autónoma Metropolitana, unidad Iztapalapa.

Castañeda Reyes, J. C. (2016). De la Constitución y las Constituciones en Egipto contemporáneo (2011-2014): análisis y reflexiones iniciales. Estudios de Asia y África, 51(1), 137-162. https://dx.doi. org/10.24201/eaa.v51i1.2185

CAstaÑEDa ReYes, J. C. (s.f.). La segunda thawra masriya: de la responsabilidad histórica de los Hermanos Musulmanes a la "Contrarrevolución" en Egipto contemporáneo. Manuscrito inédito.

Constitution of the Arab Republic of Egypt 2014 (2014). Recuperado de http://www.sis.gov.eg 
Corriente, F. (1986). Diccionario árabe-español. Madrid: Instituto Hispano-Árabe de Cultura.

DaguZAn, J.-F. (2012). Armées et société dans le monde arabe : entre révolte et conservatisme. Maghreb-Machrek, (214), 9-30. https:// doi.org/10.3917/machr.214.0007

Dawoud, K. (2015). Constitutional conflict. Al Abram Weekly. Recuperado de http://weekly.ahram.org.eg/News/13703.aspx Dessouki, A. E. H. (1982). The politics of income distribution in Egypt. En G. Abdel-Khalek y R. Tignor (Eds.), The Political economy of distribution in Egypt (pp. 55-87). Nueva York: Holmes y Meier.

EAgleton, T. (2011). Why Marx was right. New Haven: Yale University Press.

Egypt presidency reiterates planned roadmap. (3 de julio de 2013). Al Abram Online. Recuperado de http://english.ahram.org.eg/ News/75609.aspx

EL-Ghobashy, M. (1 de noviembre de 2011). Politics by other means. Boston Review. Recuperado de http://bostonreview.net/monael-ghobashy-egypt-revolution-tahrir-square

EL-Din, G. E. (6 de enero de 2011). Egypt challenged to unite. Al Abram Weekly. Recuperado de http://weekly.ahram.org.eg/ Archive/2011/1030/fr2.htm

EL-Din, G. E. (2015). Pro-Sisi coalition set to be dominant parliamentary bloc after sweeping Egypt's polls. Al Abram Weekly. Recuperado de http://english.ahram.org.eg/NewsContent/ 1/164/171645/Egypt/Egypt-Elections-/ProSisi-coalition-set-tobe-dominant-parliamentary.aspx

Elshobaki, A. (2011). Realidad y futuro de la revolución egipcia. A wraq. Revista de análisis y pensamiento sobre el mundo árabe e islámico contemporáneo, (3), 107-117.

Ezzat, D. (14 de abril de 2011). A justified fear? Al Abram Weekly Online. Recuperado de http://weekly.ahram.org.eg/archive/2011/1040/eg5.htm

EzZAT, D. (29 de enero de 2015). An elusive dream. Al Abram Weekly. Recuperado de http://weekly.ahram.org.eg/News/10315.aspx

FAHIM, K. (26 de enero de 2016). Crackdown by Egypt draws attention to an anniversary it aimed to avoid. The Nerw York Times. Recuperado de https://www.nytimes.com/2016/01/24/world/ middleeast/crackdown-by-egypt-draws-attention-to-an-anniversary-it-aimed-to-avoid.html?mcubz $=1$

FAHIM, Kareem y Kulish, N. (30 de enero de 2013). Opposition in Egypt urges unity government. The Nerw York Times. Recuperado 
de http://www.nytimes.com/2013/01/31/world/middleeast/ egypt-protests.html?mcubz $=1$

FARAG, F. (4 de julio de 2013). What Egyptians really want. Al Abram Online. Recuperado de http://english.ahram.org.eg/NewsContentP/4/75643/Opinion/What-Egyptians-really-want.aspx

FISK, R. (5 de febrero de 2011). Los manifestantes egipcios trazan plan para un futuro sin Mubarak. La Jornada, p. 24.

FIsK, R. (27 de enero de 2017). Trump, Assad y Al Sisi: rasgo común. La Jornada, p. 13.

Fontana, J. (1992). La historia después del fin de la historia. Reflexiones acerca de la situación actual de la ciencia histórica. Barcelona: Crítica.

Gardiner, A. (1909). The admonitions of an Egyptian sage from a bieratic papyrus in Leiden (Pap. Leiden 344 Recto). Liepzig: J. C. Hinrichs'sche Buchhandlung.

GoldBerG, E. (2011). Mubarakism without Mubarak. Why Egypt's military will not embrace democracy. En The new Arab revolt. What happened, what it means, and what comes next (pp. 110-114). Nueva York: Council on Foreign Relations-Foreign Affairs.

GonZÁlez Del MiÑo, P. (2014). Egipto: desafíos de una transición incierta. En P. González del Miño (Ed.), Tres años de revoluciones árabes. Procesos de cambio: repercusiones internas y regionales (pp. 140-168). Madrid: Catarata.

Grecko, T. (7 de julio de 2013). El regreso de los generales. Proceso, 36(1914), 54-56.

KirkPatRicK, D. (3 de febrero de 2015). Coming to mourn Tahrir Square's dead, and joining them instead. The New York Times. Recuperado de https://www.nytimes.com/2015/02/04/world/ middleeast/shaimaa-el-sabbagh-tahrir-square-killing-angersegyptians.html? mcubz $=1$

LANDLER, M. (3 de julio de 2013). Ambassador becomes focus of Egyptians' mistrust of U.S. The New York Times. Recuperado de http://www.nytimes.com/2013/07/04/world/middleeast/ambassador-becomes-focus-of-egyptians-mistrust-of-us. html?mcubz $=1$

Mackey, R. (3 de julio de 2013). The lede: Latest updates on Egypt's political crisis. The New York Times. Recuperado de https:// www.nytimes.com/interactive/projects/live-dashboard/egyptpolitical-crisis

Maged, A. (29 de enero de 2015). No vindication. Al Abram Weekly. Recuperado de http://weekly.ahram.org.eg/News/10258.aspx Messina, J. y Teulon, F. (2013). Egypte : d'une révolution à une au- 
tre? Maghreb-Machrek, (216), 129-142. https://doi.org/10.3917/ machr.216.0129

Millones de egipcios exigen la renuncia del presidente Mursi. (1 de julio de 2013). La Jornada, p. 27.

Morsy, A. (27 de noviembre de 2015). Below average turnout. $A l$ Abram Weekly. Recuperado de http://weekly.ahram.org.eg/ News/14865.aspx

Morsy, A. (26 de enero de 2016). An uneventful day. Al Abram Weekly. Recuperado de http://weekly.ahram.org.eg/News/ 15367.aspx

Muti, A. A. (24 y 25 de abril de 2013). The Egyptian revolution and the role of the left. Success and failure factors. Trabajo presentado en la conferencia The left and the Arab Revolutions, organizada por la Rosa Luxemburg Foundation y el Arab forum alternatives to studies, El Cairo. Recuperado de http://ayman1970.wordpress. $\mathrm{com} / 2013 / 11 / 17 /$ the-egyptian-revolution-and-the-role-of-theleft-success-and-failure-factors/

Niemuth, N. (8 de marzo de 2017). Protest shake Egypt after cut to bread subsidies. World Socialist Web Site. Recuperado de http:// www.wsws.org/en/articles/2017/03/08/egyp-m08.html

NorTH, D. y Kishore, J. (5 de enero de 2015). 2014-2015: Results and prospects. World Socialist Web Site. Recuperado de https://www. wsws.org/en/articles/2015/01/05/pers-j05.html

Off the street: How $5^{\text {th }}$ anniversary of Egypt's 2011 revolution was commemorated. (25 de enero de 2016). Al Abram Online. Recuperado de http://english.ahram.org.eg/NewsContent/1/64/185890/Egypt/Politics-/Off-the-street-How-thanniversary-of-Egypts--revol.aspx

Petras, J. (2012). The Arab revolt and the imperialist counterattack. Atlanta: Clarity Press.

Rutherford, B. K. (2013). Egypt: The origins and consequences of the January 25 uprising. En M. Hass y D. Lesch (Eds.), The Arab Spring. Change and resistance in the Middle East (pp. 35-63). Boulder: Westview Press.

SELIM, M. y Selim, G. M. (2012). Égypte : une révolution permanente, trahie ou kidnappée? Alternatives Sud, 19(2), 77-92.

Serageldin, I. (17 de julio de 2013). Egypt's inexorable revolution. Al Abram Weekly. Recuperado de http://weekly.ahram.org.eg/ News/3395.aspx

Shaoul, J. (4 de enero de 2011). Egypt destabilized in wake of bomb attack on Coptic Church. World Socialist Web Site. Recuperado de http://www.wsws.org/en/articles/2011/01/egyp-j04.html 
Shehata, D. (2010). Islamists and secularists in Egypt. Opposition, conflict, and cooperation. Londres, Nueva York: Routledge.

STERN, J. (18 de junio de 2012). Egyptian presidential elections marked by mass abstention and fraud. World Socialist Web Site. Recuperado de https://www.wsws.org/en/articles/2012/06/ egyp-j18.html

STERn, J. (15 de abril de 2013a). Leaked report reveals army torture, killings during the Egyptian Revolution. World Socialist Web Site. Recuperado de https://www.wsws.org/en/articles/2013/04/15/ egy-a15.html

Stern, J. (3 de julio de 2013b). Egyptian president Mursi vows to stay in power despite mass protests. World Socialist Web Site. Recuperado de https://www.wsws.org/en/articles/2013/07/03/ egyp-j03.html

Stern, J. (7 de septiembre de 2013c). Revolution and counterrevolution in Egypt: The political lessons. World Socialist Web Site. Recuperado de https://www.wsws.org/en/articles/2013/09/07/ egyr-s07.html

Stern, J. (9 de mayo de 2015). War in the Middle East, imperialism and the lessons of the Egyptian Revolution. World Socialist Web Site. Recuperado de https://www.wsws.org/en/articles/2015/05/09/mdjs-m09.html

TAHA, R. M. (29 de agosto de 2013). Patterson's term in Egypt officially ends. Daily Neres Egypt. Recuperado de https://dailynewsegypt.com/2013/08/29/pattersons-term-in-egypt-officially-ends/

Touring Polling Stations. (27 de noviembre de 2015). Al Abram Weekly. Recuperado de http://weekly.ahram.org.eg/News/14869. aspx

Trager, E. (2011). Letter from Cairo. The people's military in Egypt? En The new arab revolt (pp. 81-85). Nueva York: Council on Foreign Relations. Recuperado de https://www.foreignaffairs. com/articles/north-africa/2011-01-30/letter-cairo

Walsh, D. (14 de mayo de 2016). Egypt sentences 152 to prison for protest over transfer of Islands. The New York Times. Recuperado de https://www.nytimes.com/2016/05/15/world/middleeast/ egypt-sentences-51-to-prison-for-protest-over-transfer-of-islands. html 
